\title{
Role of Nucleic Acid Test (NAT) in Detection of Transfusion Transmitted Viruses in Comparison to Other Methods
}

Ekram Yassin Ebeid, Hoda Abd Ellateif Kholeif, Nancy Hassan Hussein*

Department of Clinical Pathology, Faculty of Medicine - Al-Azhar University

*Corresponding author: Nancy Hassan Hussein, Mobile: (+20)01115258990, E-Mail: nancy.barbie83@gmail.com

\begin{abstract}
Background: over the two last decades, much attention has been given to the prevention of transfusion-transmitted viral infections. Given the potential transmission of viruses during the window period, novel non-serology based approaches such as viral nucleic acid testing (NAT) have been established.

Objective: a comparative study of different methods to detect transfusion transmitted viral infections.

Materials and methods: this cross-sectional study was conducted at the Egyptian National Blood Transfusion Center (NBTC), Giza. The duration of the research was 2 months from June 2018 to august 2018. In our study 1000 donor samples were tested by ELISA and NAT tests for HBV, HCV and HIV.

Results: regarding ELISA tests of the three viruses, only 14 (1.4\%) samples were finally HBsAg reactive.

Finally, reactive HCVAb were 22 (2.2\%) samples, while only 4 (0.4\%) samples were HIV Ag-Ab finally reactive.

We found highly statistical significant difference between initial and final results of ELISA $(\mathrm{p}<0.001)$.

Regarding NAT testing of the three viruses. HBV: $5(0.5 \%)$ samples were NAT and ELISA reactive, 1 was NAT yield. HCV: $9(0.9 \%)$ samples were NAT and ELISA reactive. HIV one sample $(0.1 \%)$ was NAT and ELISA reactive, one $(0.1 \%)$ was NAT yield. Statistical significant difference was found in comparison between NAT and ELISA in HBV, $\mathrm{HCV}$, and HIV $\mathrm{p}$ values $<0.001,<0.001$, and $=0,008$ respectively.

Conclusion: we concluded that NAT and ELISA are complementary to each other. NAT is an effective method for safeguarding the blood supply.
\end{abstract}

Keywords: NAT, Transfusion transmitted viruses, HIV, HCV, HBV.

\section{INTRODUCTION}

The goal of any transfusion service is to provide adequate and safe blood and blood products that meet the needs of patients. Transfusion transmitted infections (TTIS) is a recognized complication of blood transfusion and blood products. Many of these infectious agents may cause lifetime morbidity and/or mortality. The three major viral TTIs associated with blood transfusion are human immunodeficiency (HIV), hepatitis C virus $(\mathrm{HCV})$ and hepatitis B virus (HBV) viruses ${ }^{(\mathbf{1})}$.

Whole blood may be processed into various components. Each component can then be stored under ideal storage conditions (i.e. temperature and movement) to ensure that the product is most effective when it is used. Special preservative solutions and blood bags are used to lengthen the expiry time and improve product quality; the storage conditions of the products can be optimized by the correct choice of additive, temperature, bag type and other parameters to ensure effectiveness of each component for the longest possible time ${ }^{(2)}$.

Blood safety and transfusion- transmitted infections (TTIs) are a major concern in low- resource areas. Laboratory screening of donors, a key contributor to blood safety, high- performance serologic testing and NAT are the cornerstone of TTI screening. Unlike serology, NAT has the ability to detect occult HBV infection as well as preseroconversion "window" phase infections ${ }^{(3)}$.

In the last few decades through an awareness of TTIs, a majority of countries have mandated serology based blood screening assays for HIV, HCV, and HBV. However, despite improved serological assays, the transfusion transmission of $\mathrm{HTV}, \mathrm{HCV}$, and $\mathrm{HBV}$ continues, primarily due to release of serology negative units that are infectious because of the window period (WP) ${ }^{(4)}$.

Nucleic acid testing (NAT) is a molecular technique for screening blood donations to reduce the risk of TTIs in the recipients, thus providing an additional layer of blood safety. It was introduced in the developed countries in the late 1990s and early 2000s and presently around 33 countries in the world have implemented NAT for $\mathrm{HIV}$ and around 27 countries for $\mathrm{HBV}^{(5)}$.

NAT technique is highly sensitive and specific for viral nucleic acids. It is based on amplification of targeted regions of viral ribonucleic acid (RNA) or deoxyribonucleic acid (DNA) and detects them earlier than the other screening methods thus, narrowing the window period of HIV, HBV and HCV infections. NAT also adds the benefit of resolving false reactive donations on serological methods which is very important for donor notification and counseling ${ }^{(6)}$.

NAT is a highly sensitive and advanced technique which has reduced the window period of $\mathrm{HBV}$, $\mathrm{HCV}$, HIV but it is highly technically demanding, involving issues of high costs, dedicated infrastructure facility, equipment, consumables and technical expertise. The need for NAT depends on the prevalence and incidence rate of infections in blood donor population, available resources and the evidence of benefit added when combined with serology tests. Hence the decision of starting NAT should be considered when basic quality assured blood transfusion system is already in place such as volunteer base for blood donation, provision of donor 
self-deferral, donor notification and counseling along with quality assured sensitive serological methods for testing TTIs ${ }^{(7)}$.

\section{AIM OF THE WORK}

A comparative study of different methods of detection of transfusion transmitted viral infections.

\section{MATERIALS AND METHODS}

Study Site and Duration: This cross sectional study was conducted at the Egyptian National Blood Transfusion Center (NBTC) at Dokki, Giza. The duration of the research was a period of 2 months from 20 June to 20 august 2018.

Sample Size: In NBTC, blood was collected from 1000 voluntary donors. They donated blood either in the blood bank or in the camps organized by mobile teams. Male donors were 867 (87\%), while female donors were 133 (13\%). The ratio was 6.5:1.

A detailed pre-donation questionnaire was taken during these donors registration. Information regarding risk factors as past history of surgery, prior hospitalization, history of blood transfusion and donation, occupation, high risk behavior (multi sexual partner), and history of vaccination, or any episode of jaundice were recorded. Also medical examination was done and informed consent was obtained from each donor. An approval of the study was obtained from Al- Azhar University academic and ethical committee.

\section{Specimen Collection, storage and handling:}

Sample collection was carried out at the beginning of phlebotomy by 16-17 gauge needles, $5 \mathrm{ml}$ venous blood was drawn from each donor in plain tube (Becton Dickenson) under complete aseptic condition and used to obtain serum by centrifugation and the following tests were done. Another EDTA tube was used to collect plasma samples for NAT testing.

\section{Serological Tests :}

$\bigcirc$ Hepatitis $B$ surface antigen using Bioelisa 0,3 kits (biokit, Spain) :

Direct ELISA test for qualitative detection of hepatitis B surface antigen (HBsAg) in human serum, the plate was coated with HBsAb. Sensitivity range of this test was (93.4-100\%).

- Anti HCV antibodies using $4^{\text {th }}$ generation ELISA Diagnostic Bioprobe s.r.l (Diapro, Italy):

Fourth generation direct enzyme immunoassay (ELISA) for the detection of antibodies to hepatitis $\mathrm{C}$ virus in human sera. Sensitivity range of this test was (81-99.9\%).

$\circ$ HIV Ag-Ab using HIV $4^{\text {th }}$ generation Genscreen ULTRA Biorad kits (France):

The Genscreen ${ }^{\mathrm{TM}}$ ULTRA HIV Ag-Ab is a qualitative direct enzyme immunoassay kit for the detection of HIV p24 antigen and antibodies to HIV-1 (groups M and O) and HIV-2 in human serum. This kit was used for both
HIV Ag and HIV Ab screening. The sensitivity of this test was $(99.9 \%)$.

\section{NAT testing:}

Using the PROCLEIX® TIGRIS $®$ System, individual -NAT (Novartis, Switzerland) depending on TMA technology.

All samples were tested individually. The Procleix ${ }^{\circledR}$ Ultrio ${ }^{\circ}$ Assay provides simultaneous detection of HIV-1 RNA, HCV RNA and HBV DNA in human plasma using transcription mediated amplification technology (TMA).

The TMA assay involves three main steps utilizing three proprietary technologies:

(a) Target capture based sample preparation,

(b) Transcription-mediated amplification,

(c) Detection by hybridization.

All performed in a single tube. All three assays incorporate an internal control to validate each reaction (8).

\section{Specimen collection, storage, and handling:}

A. Blood specimens which were collected in plastic tubes on EDTA were used.

B. Plasma was obtained by centrifugation of each tube at $3500 \mathrm{rpm}$ for 10 minutes; specimens were centrifuged within 72 hours of collection, because specimen stability is affected by high temperature. Specimens were stored at $8^{\circ} \mathrm{C}$ For 72 hours, and up to $30^{\circ} \mathrm{C}$ for 24 hours. Otherwise, specimens were stored at $2^{\circ}$ from $8^{\circ} \mathrm{C}$.

Decontamination was done before preparing reagents because of the extremely sensitive nature of the test. Laboratory bench surfaces and pipettes were decontaminated daily with $0.5 \%$ sodium hypochlorite in water (diluted bleach). Bleach was allowed to contact surfaces for at least 15 minutes, which was followed by a water rinse.

\section{Assay procedure (fully automated):}

a) Target capture: viral RNA and DNA were isolated from specimens via the use of target capture. The specimen was treated with a detergent to solubilize the viral envelope, denature proteins and release viral genomic RNA and/or DNA. Oligonucleotides (capture oligonucleotides) that are homologous to highly conserved regions of HIV-1, HCV, and HBV were hybridized to the HIV-1 RNA, HCV RNA, or HBV DNA target, if present, in the test specimen. The hybridized target was then captured onto magnetic microparticles that are separated from the specimen in a magnetic field. Wash steps were utilized to remove extraneous components from the reaction tube. Magnetic separation and wash steps were performed with a target capture system.

b) Transcription-mediated amplification: occurred via TMA, which is a transcription-based nucleic acid amplification method that utilizes two enzymes, reverse transcriptase and RNA polymerase. 
c) Detection by hybridization: was achieved by hybridization protection assay (HPA) using singlestranded nucleic acid probes with chemiluminescent labels that are complementary to the amplicon. The labeled nucleic acid probes hybridize specifically to the amplicon. The selection reagent differentiates between hybridized and unhybridized probes by inactivating the label on unhybridized probes. During the detection step, the chemiluminescent signal produced by the hybridized probe was measured in a luminometer and is reported as relative light units (RLU).

\section{Data collection and analysis:}

The data derived was recorded in NAT results form and analysis was done to compare results and detect seronegative reactive NAT donor samples (NAT yield). Quality assurance in all tests was maintained as per national standards. Final serology and NAT results were obtained in release form.

\section{Statistical analysis}

Recorded data were analyzed using the statistical package for social sciences, version 20.0 (SPSS Inc., Chicago, Illinois, USA). Quantitative data were expressed as mean \pm standard deviation (SD). Qualitative data were expressed as frequency and percentage.

\section{The following tests were done:}

- Independent-samples t-test of significance was used when comparing between two means.

- Chi-square $\left(\mathrm{x}^{2}\right)$ test of significance was used in order to compare proportions between two qualitative parameters.

- The confidence interval was set to $95 \%$ and the margin of error accepted was set to $5 \%$. The p-value was considered significant as the following:

- Probability (P-value)

- P-value $<0.05$ was considered significant.

- P-value $<0.001$ was considered as highly significant.

- P-value $>0.05$ was considered insignificant.

\section{RESULTS}

The largest age group among donors in this study was between 20 to 30 years 432 [43.2\%], whereas the smallest group was of donors above 50 years old 43 [4.3\%]. Most of donors 629 [62.9\%] previously donated blood; only 37 donors were regular donors in National Blood Transfusion Centre (NBTC), while donors donated blood for $1^{\text {st }}$ time were $371(37.1 \%)$ (Table 1).
Table 1: Number of donors from each age group and in relation to previous donation.

\begin{tabular}{|l|c|c|}
\hline \multicolumn{2}{|c|}{ Number } & Percentage \\
\hline Age & 25 & $2.5 \%$ \\
$<20$ & 432 & $43.2 \%$ \\
$20-30$ & 325 & $32.5 \%$ \\
$30-40$ & 175 & $17.5 \%$ \\
$40-50$ & 43 & $4.3 \%$ \\
$>50$ & & \\
\hline Gender & 867 & $86.7 \%$ \\
Male & 133 & $13.3 \%$ \\
Female & & \\
\hline Previous & \\
donation & & $3.7 \%$ \\
Regular donor & 37 & $96.3 \%$ \\
Non-regular & 963 & $37.1 \%$ \\
\hline $1^{\text {st time }}$ donation & 371 & \\
\hline
\end{tabular}

\section{Comparison between initial and final reactivity of} HBsAg, HCVAb and HIVAg-Ab by ELISA:

In the current study comparing between the results of HBsAg, HCVAb and HIVAg-Ab by ELISA test from $1^{\text {st }}$ time (initially reactive) to duplicate testing using the same kits, a highly statistically significant difference were found $(\mathrm{p}<0.001)$ for each parameter (tables $\mathbf{2 , 3}$ and 4).

Regarding ELISA testing of HBSAg, 23 (2.3\%) samples were initially reactive, while 977 (97.7\%) samples were non-reactive.

By repeating the test using the same ELISA kit, 14 $(1.4 \%)$ samples were finally reactive, while $9(0.9 \%)$ samples were false positive initially. The total negative samples were 986 (98.6\%) (Table 2).

Table 2: Comparison between initial reactive $\mathrm{HBs}$ Ag and final reactive HBs Ag by ELISA test.

\begin{tabular}{|c|c|c|c|c|c|}
\hline & \multicolumn{2}{|c|}{$\begin{array}{c}\text { Final Reactivity } \\
\text { HBs Ag }\end{array}$} & \multirow[t]{2}{*}{ Total } \\
\hline & & & $\mathbf{N}$ & $\mathbf{R}$ & \\
\hline \multirow{4}{*}{$\begin{array}{c}\text { Initial } \\
\text { Reactivity } \\
\text { HBs Ag }\end{array}$} & \multirow[b]{2}{*}{$\mathbf{N}$} & Count & 977 & 0 & 977 \\
\hline & & $\begin{array}{c}\% \text { within Final } \\
\text { Reactivity HBs Ag }\end{array}$ & $99.1 \%$ & $0.0 \%$ & $97.7 \%$ \\
\hline & \multirow[b]{2}{*}{$\mathbf{R}$} & Count & 9 & 14 & 23 \\
\hline & & $\begin{array}{c}\% \text { within Final } \\
\text { Reactivity HBs Ag }\end{array}$ & $0.9 \%$ & $100.0 \%$ & $2.3 \%$ \\
\hline \multirow{2}{*}{\multicolumn{2}{|c|}{ Total }} & Count & 986 & 14 & 1000 \\
\hline & & $\begin{array}{c}\% \text { within Final } \\
\text { Reactivity HBs Ag }\end{array}$ & $100.0 \%$ & $100.0 \%$ & $100.0 \%$ \\
\hline
\end{tabular}

$\mathrm{N}=$ non-reactive.

Regarding ELISA testing of HCVAb, 30 (3\%) samples were initially reactive, while 970 (97\%) samples were non-reactive.

By repeating the test using the same ELISA kit, 22 (2.2\%) samples were finally reactive, while $8(0.8 \%)$ 
samples were false positive initially. The total negative

Table 3: Comparison between initial to final reactive HCVAb by ELISA test.

\begin{tabular}{|c|c|c|c|c|c|}
\hline & \multicolumn{2}{|c|}{$\begin{array}{c}\text { Final Reactivity } \\
\text { HCV }\end{array}$} & \multirow[t]{2}{*}{ Total } \\
\hline & & & $\mathbf{N}$ & $\mathbf{R}$ & \\
\hline \multirow{4}{*}{$\begin{array}{c}\text { Initial } \\
\text { Reactivity } \\
\text { HCV }\end{array}$} & \multirow[b]{2}{*}{$\mathbf{N}$} & Count & 970 & 0 & 970 \\
\hline & & $\begin{array}{l}\% \text { within Final } \\
\text { Reactivity HCV }\end{array}$ & $99.2 \%$ & $0.0 \%$ & $97.0 \%$ \\
\hline & \multirow[b]{2}{*}{$\mathbf{R}$} & Count & 8 & 22 & 30 \\
\hline & & \begin{tabular}{|l|}
$\%$ within Final \\
Reactivity HCV
\end{tabular} & $0.8 \%$ & $100.0 \%$ & $3.0 \%$ \\
\hline \multirow{2}{*}{\multicolumn{2}{|c|}{ Total }} & Count & 978 & 22 & 1000 \\
\hline & & $\begin{array}{l}\% \text { within Final } \\
\text { Reactivity HCV }\end{array}$ & $100.0 \%$ & $100.0 \%$ & $100.0 \%$ \\
\hline
\end{tabular}

$\mathrm{P}<0.001=$ highly significant $\mathrm{R}=$ reactive, $\mathrm{N}=$ non-reactive.

Regarding ELISA testing of HIVAg-Ab, 5 (0.5\%) samples were initially reactive, while 995 (99.5\%) samples were non-reactive.

By repeating the test using the same ELISA kit, 4 $(0.4 \%)$ samples were finally reactive, while $1(0.1 \%)$ sample was false positive initially. The total negative samples were 996 (99.6\%) (table 4).

Table 4: Comparison between initial to final reactive HIVAg-Ab by ELISA.

\begin{tabular}{|c|c|c|c|c|c|}
\hline & \multicolumn{2}{|c|}{$\begin{array}{c}\text { Final Reactivity } \\
\text { HIV }\end{array}$} & \multirow[t]{2}{*}{ Total } \\
\hline & & & \begin{tabular}{|l|}
$\mathbf{N}$ \\
\end{tabular} & $\mathbf{R}$ & \\
\hline \multirow{4}{*}{$\begin{array}{c}\text { Initial } \\
\text { Reactivity } \\
\text { HIV }\end{array}$} & \multirow[b]{2}{*}{$\mathbf{N}$} & Count & 995 & 0 & 995 \\
\hline & & $\begin{array}{l}\% \text { within Final } \\
\text { Reactivity HIV }\end{array}$ & $99.9 \%$ & $0.0 \%$ & $99.5 \%$ \\
\hline & \multirow[b]{2}{*}{$\mathbf{R}$} & Count & 1 & 4 & 5 \\
\hline & & $\begin{array}{l}\% \text { within Final } \\
\text { Reactivity HIV }\end{array}$ & $0.1 \%$ & $100.0 \%$ & $0.5 \%$ \\
\hline \multirow{2}{*}{\multicolumn{2}{|c|}{ Total }} & Count & 996 & 4 & 1000 \\
\hline & & $\begin{array}{l}\% \text { within Final } \\
\text { Reactivity HIV }\end{array}$ & $100.0 \%$ & $100.0 \%$ & $100.0 \%$ \\
\hline
\end{tabular}

$\mathrm{P}<0.001=$ highly significant, $\mathrm{R}=$ reactive, $\mathrm{N}=$ non-reactive.

\section{Comparing ELISA and NAT results}

Regarding NAT testing of HBV $6(0.6 \%)$ samples were reactive, $5(0.5 \%)$ of them were finally reactive by ELISA testing of HBVsAg too, while $1(0.1 \%)$ sample was finally non-reactive by ELISA testing of HBVsAg (NAT yield).

N.B: the NAT yield was defined as NAT-positive test result that was negative in serologic testing.

While 994 (99.4\%) samples were nonreactive by NAT testing of HBV, 985 (98.5\%) of them were finally non-reactive by ELISA too, while $9(0.9 \%)$ were finally reactive by ELISA.

Regarding ELISA testing of HBVsAg 14 (1.4\%) samples were finally reactive, $5(0.5 \%)$ of them were reactive by NAT too, while $9(0.9 \%)$ were not reactive by NAT.

Regarding ELISA testing of HBVsAg 986 (98.6\%) samples were finally non-reactive, $985(98.5 \%)$ of them samples were 978 (97.8\%) (table 3).

were non-reactive by NAT, while $1(0.1 \%)$ sample was non-reactive by NAT (table 5).

Table 5: Comparison between results of NAT and ELISA of HBV.

\begin{tabular}{|c|c|c|c|c|c|}
\hline & \multicolumn{2}{|c|}{ NAT HB } & \multirow[t]{2}{*}{ Total } \\
\hline & & & $\mathbf{N}$ & $\mathbf{R}$ & \\
\hline \multirow{4}{*}{$\begin{array}{c}\text { Final } \\
\text { Reactivity } \\
\text { HBs Ag }\end{array}$} & \multirow[b]{2}{*}{$\mathbf{N}$} & Count & 985 & 1 & 986 \\
\hline & & $\begin{array}{c}\% \text { within } \\
\text { NAT HB Ag }\end{array}$ & $99.1 \%$ & $16.7 \%$ & $98.6 \%$ \\
\hline & \multirow[b]{2}{*}{$\mathbf{R}$} & Count & 9 & 5 & 14 \\
\hline & & $\begin{array}{c}\% \text { within } \\
\text { NAT HB Ag }\end{array}$ & $0.9 \%$ & $83.3 \%$ & $1.4 \%$ \\
\hline \multirow{2}{*}{\multicolumn{2}{|c|}{ Total }} & Count & 994 & 6 & 1000 \\
\hline & & $\begin{array}{c}\% \text { within } \\
\text { NAT HB Ag }\end{array}$ & $100.0 \%$ & $100.0 \%$ & $100.0 \%$ \\
\hline
\end{tabular}

$\mathrm{P}<0.001=$ highly significant.

$\mathrm{R}=$ reactive,

$\mathrm{N}=$ non-reactive.

In this study we found a statistical significant difference between the results of HBV using NAT testing in comparison to ELISA method, p value $<0.001$ (highly significant).

Regarding ELISA testing of HCVAb finally reactive samples were $22(2.2 \%), 13(1.3 \%)$ of them were reactive by NAT testing too, while $9(0.9 \%)$ of them were non-reactive by NAT.

Regarding NAT testing of HCV 987(98.7\%) samples were non-reactive, 9 of them were reactive by ELISA testing of HCVAb too, while $978(97.8 \%$ ) were non-reactive by ELISA testing.

From the total samples that were non-reactive HCV NAT we found that $0.9 \%$ were repeated reactive by ELISA HCVAb, while $99.1 \%$ were non-reactive by Elisa HCVAb.

In this study we found a statistical significant difference between the results of HCV using NAT testing in comparison to ELISA method, p value $<0.001$ (highly significant) (Table 6).

Table 6: Comparison between NAT and ELISA for detection of $\mathrm{HCV}$ in blood donors.

\begin{tabular}{|c|c|c|c|c|c|}
\hline & \multicolumn{2}{|c|}{ NAT HCV } & \multirow[t]{2}{*}{ Total } \\
\hline & & & $\mathbf{N}$ & $\mathbf{R}$ & \\
\hline \multirow{4}{*}{$\begin{array}{c}\text { Final } \\
\text { Reactivity } \\
\text { HCV }\end{array}$} & & Count & 978 & 0 & 978 \\
\hline & $\mathbf{N}$ & $\begin{array}{l}\% \text { within } \\
\text { NAT HCV }\end{array}$ & $99.1 \%$ & $0.0 \%$ & $97.8 \%$ \\
\hline & & Count & 9 & 13 & 22 \\
\hline & $\mathbf{R}$ & $\begin{array}{l}\% \text { within } \\
\text { NAT HCV }\end{array}$ & $0.9 \%$ & $100.0 \%$ & $2.2 \%$ \\
\hline \multirow{2}{*}{\multicolumn{2}{|c|}{ Total }} & Count & \begin{tabular}{|l|}
987 \\
\end{tabular} & 13 & 1000 \\
\hline & & $\begin{array}{r}\% \text { within } \\
\text { NAT HCV }\end{array}$ & $100.0 \%$ & $100.0 \%$ & $100.0 \%$ \\
\hline
\end{tabular}

$\mathrm{P}<0.001=$ highly significant

$\mathrm{R}=$ reactive,

$\mathrm{N}=$ non-reactive. 
Regarding NAT testing of HIV $2(0.2 \%)$ samples were reactive, $1(0.1 \%)$ of them was finally reactive by ELISA testing of HIVAb, while the other $1(0.1 \%)$ was non-reactive.

Regarding NAT testing of HIV 998 (99.8\%) samples were non-reactive, $3(0.3 \%)$ of them were finally reactive by ELISA, while 995 (99.5\%) were non-reactive by ELISA testing.

Regarding positive ELISA testing of HIVAb 4 $(0.4 \%)$ samples were finally reactive, $1(0.1 \%)$ of them was reactive by NAT testing too, while $3(0.3 \%)$ were non-reactive by NAT.

While ELISA testing of HIVAb 996 (99.6\%) samples were finally non-reactive by ELISA, $1(0.1 \%)$ of them was reactive by NAT, while $995(99.5 \%)$ were nonreactive by NAT.

In this study we found a statistical significant difference between the results of HIV using NAT testing in comparison to ELISA method, p value $<0.008$ (Table 7).

Table 7: Comparison between NAT and ELISA for detection of HIV in blood donors.

\begin{tabular}{|c|c|c|c|c|c|}
\hline \multirow{2}{*}{\multicolumn{3}{|c|}{ 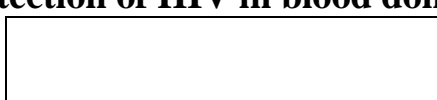 }} & \multicolumn{2}{|c|}{ NAT HIV } & \multirow[t]{2}{*}{ Total } \\
\hline & & & $\mathbf{N}$ & $\mathbf{R}$ & \\
\hline \multirow{4}{*}{$\begin{array}{l}\text { Final } \\
\text { Reacti } \\
\text { vity } \\
\text { HIV }\end{array}$} & \multirow[b]{2}{*}{$\mathbf{N}$} & Count & 995 & 1 & 996 \\
\hline & & $\begin{array}{l}\% \text { within } \\
\text { NAT HIV }\end{array}$ & $99.7 \%$ & $50.0 \%$ & $99.6 \%$ \\
\hline & \multirow[b]{2}{*}{$\mathbf{R}$} & Count & 3 & 1 & 4 \\
\hline & & $\begin{array}{l}\% \text { within } \\
\text { NAT HIV }\end{array}$ & $0.3 \%$ & $50.0 \%$ & $0.4 \%$ \\
\hline \multirow{2}{*}{\multicolumn{2}{|c|}{ Total }} & Count & 998 & 2 & 1000 \\
\hline & & $\begin{array}{l}\% \text { within } \\
\text { NAT HIV }\end{array}$ & $100.0 \%$ & $100.0 \%$ & $100.0 \%$ \\
\hline
\end{tabular}

$\mathrm{P}=0.008=$ significant. $\quad, \mathrm{R}=$ reactive, $\mathrm{N}=$ non-reactive .

21 samples were seropositive (positive ELISA both initially and on retesting too), NAT negative, they were as follow:

- HBV: 9 samples $(0.9 \%)$.

- HCV: 9 samples $(0.9 \%)$.

- HIV: 3 samples $(0.3 \%)$ (Table 8).

Table 8: number and percentage of ELISA positive, NAT negative samples (seroyield)

\begin{tabular}{|c|c|c|c|}
\hline Parameters & $\begin{array}{c}\text { Number } \\
\text { of } \\
\text { samples }\end{array}$ & $\begin{array}{c}\text { Percentage } \\
\text { to total } \\
\text { tested } \\
\text { samples }\end{array}$ & $\begin{array}{c}\text { Percentage } \\
\text { to NAT } \\
\text { positive } \\
\text { samples }\end{array}$ \\
\hline HBV & 9 & $0.9 \%$ & $42.8 \%$ \\
\hline HCV & 9 & $0.9 \%$ & $42.8 \%$ \\
\hline HIV & 3 & $0.3 \%$ & $14.2 \%$ \\
\hline TOTAL & 21 & $2.1 \%$ & $100 \%$ \\
\hline
\end{tabular}

\section{DISCUSSION}

In our study 1000 donor samples were tested, all of them were voluntary $(100 \%)$, Most of donors were males 867 [86.7\%], while 133 [13.3\%] were females. Also the largest age group among donors in this study was between 20 to 30 years 432 [43.2\%], whereas the smallest group was of donors above 50 years old 43[4.3\%]. Most of donors 629 [62.9\%] donated blood previously; only 37 donors were regular donors.

In the current study by using ELISA kits for HBsAg, $\mathrm{HCVAb}$ and HIVAg-Ab, we found that the prevalences of these parameters were $1.4 \%, 2.2 \%$, and $0.4 \%$ respectively.

Sarah et al. ${ }^{(9)}$ in their study, three hundred and sixty-one blood donors, $80 \%$ male and $20 \%$ female, were tested, the age of donors ranged from less than 20 to more than 50 years. The largest age group (41.83\%) of blood donors occurred in the group aged from 20 to 29 years. The lowest rate was found in blood donors more than 50 years $(1.66 \%)$. And $36.84 \%$ were in 30 39 years and $17.73 \%$ were in group $40-49$ years, a total of 276 blood donors were normally non-infected and 85 were TTIs infected.

In this study samples were tested using direct ELISA test for qualitative detection of Hepatitis B surface antigen (HBsAg), out of 1000 samples 23 (2.3\%) were initially reactive, when retested in duplicate using the same kits $14(1.4 \%)$ of them were repeated reactive while 9 samples $(0.9 \%)$ were negative (false seroreactive).

Similarly Wasfi ${ }^{(\mathbf{1 0})}$ reported that in his study in Alexandria, Egypt, which included 3420 samples tested for hepatitis B surface antigen (HBsAg), a total of 47 donors $(1.4 \%)$ were positive for HBsAg. This rate was lower than previous studies in Egypt, perhaps due to predonation screening which excludes those known to be at high risk of contracting bloodborne infections or who had other contraindications to blood donation.

In our study regarding ELISA testing of HCVAb we used fourth generation direct enzyme immunoassay (ELISA) for the detection of antibodies to hepatitis C virus. Out of the 1000 samples tested, 30 samples (3\%) were initially reactive, when retested in duplicate using the same kits $22(2.2 \%)$ of them were repeated reactive while 8 samples $(0.8 \%)$ were negative (false seroreactive).

The seroprevalence of HCV in this study is higher than what Shah et al. ${ }^{(11)}$ found in their study. A total of 2037 blood samples were collected from donors, the blood was screened by rapid and ELISA tests to detect $\mathrm{HCV}$ infection. The detected infection rate of $\mathrm{HCV}$ in blood donors was $0.5 \%$ (8/2037).

A study included 456 serum samples from blood donor at Al-Hussien Hospital Blood Bank was done by Ibrahim et al. ${ }^{(12)}$. Serum samples were subjected to HCV antibody detection by ELISA, Chemiluminescence tests and HCV-RNA detection by RT-PCR assay. They considered PCR as a standard test 
to evaluate ELISA and Chemiluminescence. The detected percentage of infectivity of donors in that study was $9 \%$ by ELISA, which is more than the prevalence in our study, and $13 \%$ by chemiluminescence and $8 \%$ by PCR. The percentage of false negativity of HCV antibody by ELISA and CIA when compared with PCR assay were $0.96 \%$ and $1.5 \%$ respectively. The false positivity of $\mathrm{HCV}-\mathrm{Ab}$ by ELISA and CIA as compared by PCR were $14.6 \%$ (6 out of 41 ) and $26.6 \%$ (16 out of 60 ). The false positive $\mathrm{HCVAb}$ in our study was $(0.8 \%)$, while there was no false negative HCVAb in comparison to NAT testing. Ibrahim et al. ${ }^{(12)}$, reported that ELISA is more sensitive and specific than chemiluminescence for blood transfusion screening, but at gray zone results. They concluded that nucleic acid testing (PCR) should be used as confirmatory method, and it is very important to screen blood donors using RT-PCR to avoid false positive and false negative results.

In our study 1000 blood donors were tested using a qualitative direct enzyme immunoassay kit for the detection of HIV p24 antigen and antibodies to HIV-1 and HIV-2 in human plasma as screening test. Five samples $(0.5 \%)$ were initially reactive, when retested in duplicate using the same kits $4(0.4 \%)$ of them were repeated reactive while 1 samples $(0.1 \%)$ was negative (false seroreactive).

Egypt is considered to have a low HIV prevalence, with estimates of less than $1 \%$ of the population as HIV positive. However, unsafe behavior among at-risk populations sets Egypt at risk for a broader epidemic. HIV screening among blood donors is therefore a key safety issue in addition to screening for other transfusion-transmitted infections (TTIs) such as HBV, $\mathrm{HCV}$, and syphilis. According to the WHO guidelines, screening of all blood for TTIs should be mandatory.

Few reports were published on the prevalence of HIV among voluntary blood donors in Egypt. A retrospective study on voluntary student blood donors in Egypt was done by Senosy ${ }^{(13)}$ and showed that out of the 26442 blood donors whose records were examined for the presence of HIV over the 5-year period, the prevalence of HIV antibodies (Abs) was $0.1 \%$ (14 donors) and this is lower than HIV seroprevalence in our study (0.4.\%). In Senosy ${ }^{(13)}$ study more than $50 \%(57.1 \%$; 8/14) of HIV positive donors were between 20 and 29 years of age and $28.6 \%(4 / 14)$ were between 30 and 39 years of age.

In our study the majority (22/40) (55\%) of infection was HCV, followed by HBV (14/40) (35\%), while the least was HIV 4 (4/40) (10\%).

Sarah et al. ${ }^{\left({ }^{9}\right)}$ found that the percent of donors who were infected with $\mathrm{HCV}$ was $(7.2 \%)$ while the percent of donors infected with HIV was (4.7\%). HBsAg was detected in $8.6 \%$ of donors. These prevalences of TTIs are higher than in the current study (HBV: $1.4 \%, \mathrm{HCV}$ : $2.2 \%$, and HIV: $0.4 \%$ ).

On the other hand Kumari et al. ${ }^{(14)}$ reported that, on screening of 106,306 blood units for TTIs (by using third generation enzyme linked immunoadsorbent assay technique) 1,462 (1.37\%) donors were found positive for one of the TTIs. Highest prevalence was for HBV 970 donors $(0.91 \%)$. which was followed by, HCV 127 donors $(0.11 \%)$, HIV 72 donors $(0.06 \%)$. Their results were much lower than the prevalence of HBV (1.4\%), HCV (2.2\%) and HIV (0.4\%) in our study.

In our study regarding NAT testing of $\mathrm{HBV}$ we found that out of 1000 tested donations, 6 samples $(0.6 \%)$ showed reactivity by ultrio plus, 5 samples $(0.5 \%)$ showed reactivity by both NAT and ELISA testing of HBsAg, while one of them $(0.1 \%)$ was HBV NAT yield (reactive initially by ultrio plus, seronegative by ELISA testing of HBsAg and on discriminatory testing it was dHBV positive); so HBV NAT yield rate in this study was $1: 1000$

In the current study there was one sample HBV NAT yield (false seronegative and NAT reactive), similar to a previous case study by O'Flaherty et al. ${ }^{(15)}$. Lookback was initiated upon notification of an acute HBV infection in a repeat Irish donor, 108 days postdonation. The donation screened non- reactive by individual- donation nucleic acid testing (ID- NAT) using the Procleix Ultrio Elite multiplex assay and again when the archived sample was retested, but the discriminatory assay for $\mathrm{HBV}$ was reactive. The immunocompromised recipient of the implicated red cell component was tested 110 days post- transfusion, revealing a HBV DNA viral load of $470 \mathrm{IU} / \mathrm{ml}$. Genotype $\mathrm{C} 2$ sequences identical across two regions of the HBV genome were found in samples from the donor and recipient.

In this study regarding NAT testing of $\mathrm{HCV}$ we found that out of 1000 tested samples by ultrio plus, 13 samples $(1.3 \%)$ were reactive ( HCV NAT positive). There were no HCV NAT yield samples (all NAT reactive samples showed seroreactivity on ELISA testing of HCVAb).

In Italy nucleic acid testing (NAT) became mandatory for hepatitis C virus (HCV) in 2002 and for human immunodeficiency virus (HIV) and hepatitis B virus in $2008^{(\mathbf{1 6})}$.

In our study regarding NAT testing of HIV we found that out of 1000 tested samples $2(0.2 \%)$ were initially reactive by ultrio plus; 1 of them $(0.1 \%)$ was HIV NAT yield (initially reactive NAT and seronegative). HIV NAT yield rate in our study was 1:1000, and on discriminatory testing it was d-HIV positive, while the other one was seroreactive and initially NAT positive too.

Similarly Makroo et al. (17) studied the data of 180,477, Individual donor nucleic acid testing (ID-NAT) was performed for all donors using Proclei $\mathrm{x}^{\circledR}$ Ultrio $^{\circledR}$ assay and further discriminatory assays were performed for the all initial ID-NAT reactive samples to differentiate between HIV RNA, HBV DNA 
and HCV RNA. The overall seroprevalence of HIV was $440(0.24 \%)$.

In this study all blood samples were tested by IDNAT; there were 22 samples (2.2\%) initially reactive, while 978 (97.8\%) were initially negative, 1 sample $(0.1 \%)$ was initially reactive and on discriminatory NAT testing was negative (false positive). Incidence of HBV, HCV and HIV NAT samples among total tested samples were as following, HBV reactive samples were 6 samples $(0.6 \%), \mathrm{HCV}$ reactive samples were 13 samples $(1.3 \%)$, HIV reactive samples were 2 sample (0.2\%). Discriminatory NAT testing was done and the incidence of blood born viruses in NAT yield samples as follows, HBV NAT yield was 1 sample $(0.1 \%)$, no HCV NAT yield samples were found, and HIV NAT yield was 1 sample $(0.1 \%)$.

In our study we found that 14 samples (1.4\%) were repeated reactive (seroreactive) HBV by ELISA testing, while 22 samples $(2.2 \%)$ seroreactive $\mathrm{HCV}$, and 4 samples $(0.4 \%)$ were seroreactive HIV.

In our study 21 samples were seropositive (positive ELISA both initially and on retesting too). NAT negative (seroyield) samples were as follow, 9 samples seroyield HBV (0.9\%), 9 samples HCV (0.9\%) and 3 samples seroyield HIV $(0.3 \%)$.

Most of comparative studies similarly reported NAT yield samples, which were negative by ELISA testing and carrying risk of TTIs even to more than one recipient as the single whole blood unit can be processed into 3 units of blood components.

The prevalence of these viruses in our sample tested by ID-NAT is $0.06 \%, 0.71 \%$, and $0.63 \%$ for HIV- 1 , HCV and $\mathrm{HBV}$ respectively.

In countries with high incidence of infection with significant number of window period donations, NAT can serve as a valuable tool along with other serological testing in high prevalence, resource constrained countries to achieve the goal of zero risk TTIs of blood ${ }^{(\mathbf{1 8}, 19)}$.

In our study we used individual NAT testing using The Procleix ${ }^{\circledR}$ Ultrio ${ }^{\circledR}$ Assay, which provides simultaneous detection of HIV-1 RNA, HCV RNA and HBV DNA in human plasma using transcription mediated amplification technology (TMA).

In a study that compared the sensitivity of IDand MP-NAT testing as assessed by dilution of NAT yield samples; the authors observed that samples with high viral load were detected by all dilutions, but $67 \%$ of samples of low viral load were missed by MP-NAT and concluded that ID-NAT is ideal methodology for TTIs screening ${ }^{(20)}$.

\section{CONCLUSION}

- Finally, we concluded that NAT and ELISA are complementary to each other. With the increased prevalence of TTIs and incidence of infection and lack of public education about self-deferral, NAT can be an effective method for safeguarding the blood supply. Nucleic acid testing could detect HIV, HBV and HCV cases in blood donor samples that were undetected by serological tests. Also it can solve false reactivity results of serological test, providing safe blood components to patients.

\section{RECOMMENDATIONS}

- NAT implementation together with ELISA serological testing is recommended to be mandatory in screening of blood donors to reduce the residual risk of TTIs in every blood bank in Egypt.

\section{REFERENCES}

1. Rizal D (2017): Transfusion Transmitted Infections in Blood Donors. Journal Fikrah Jilid., 8:49-61.

2. Strauss D (2019): Transfusion Medicine and Hemostasis, Component Preparation and Manufacturing. $3^{\text {rd }}$ ed: Pp. 53-58.

3. Weimer A, Tagny C, Tapko J, Gouws C, Tobian A, Ness P, Bloch E (2019): Blood transfusion safety in subSaharan Africa: A literature review of changes and challenges in the 21st century. Transfusion, 59: 412-427.

4. Chatterjee K, Coshic P, Borgohain M, Premchand, Thapliyal RM, Chakroborty S (2012): Individual donor nucleic acid testing for blood safety against HIV-1 and hepatitis $\mathrm{B}$ and $\mathrm{C}$ viruses in a tertiary care hospital. Natl Med J India, 25:207-209.

5. Kumar R, Gupta S, Kaur A, Gupta M (2015): Individual donor-nucleic acid testing for human immunodeficiency virus-1, hepatitis $C$ virus and hepatitis $B$ virus and its role in blood safety. Asian Journal of Transfusion Science, 9(2): 199.

6. Shyamala V (2014): Factors in enhancing blood safety by nucleic acid technology testing for human immunodeficiency virus, hepatitis $\mathrm{C}$ virus and hepatitis B virus. Asian J Transfus Sci., 8:13-18.

7. Hans R, Marwaha N (2014): Nucleic acid testing-benefits and constraints. Asian J Transfus Sci., 8(1):2-3.

8. Kacian DL, Fultz TJ (1955): Nucleic acid sequence amplification methods. U.S. paten. https://pdfs.semanticscholar. org/517d/9fe47 abb3775853 d85e497dde7ad22ffda0e.pdf

9. Sarah YA, El Halim AE, Ali AL (2016): Seropositivity of TTIs among blood donors in Hail, Saudi Arabia, from 2014 to 2015. Asian Pacific Journal of Tropical Disease, 6(2): 141-146.

10. Wasfi O (2011): Prevalence of hepatitis B surface antigen and hepatitis $\mathrm{C}$ virus antibodies among blood donors in Alexandria, Egypt. East Mediterr Health J., 17(3):238-42.

11. Shah G B, Gurung K, Baral B P, Gurung $\mathbf{R}$, Bhattachan B (2018): Hepatitis B and C Virus Infections among Blood Donors in Blood Transfusion Center, Pokhara, Nepal: Seroprevalence and its Associated Risk Factors. Nepal Journal of Biotechnology, 6(1): 33-38.

12. Ibrahim A M, Abo-El-Azaem N G M, Mohamed M A, Ghaith A A, Ahmed S H, Zaki M M (2018): Evaluation of some available HCV antibody detection tests (ELISA, Chemiluminescence, Immune Assay) and RT-PCR assay in the diagnosis of Hepatitis $\mathrm{C}$ virus infection. The Egyptian Journal of Hospital Medicine, 72(7): 48744879.

13. Senosy S A (2015): Prevalence of HIV among blood donors at Beni-Suef University Hospital Blood Bank, Egypt. The 
Journal of the Egyptian Public Health Association, 90(4): 116-157.

14. Kumari S, Kumar R, Srivastava R K (2016): Spectrum of Transfusion Transmitted Infections among Apparently Healthy Blood Donors in Blood Bank RIMS Ranchi From 2008 to 2014. Open Science Journal, 1(2): 550-554.

15. O'Flaherty N, Ushiro- Lumb I, Pomeroy L, Ijaz S, Boland F, De Gascun C, O'Riordan J (2018): Transfusion- transmitted hepatitis B virus (HBV) infection from an individual- donation nucleic acid (ID- NAT) non- reactive donor. Vox sanguinis., 113(3): 300-303.

16. Velati C, Romanò L, Piccinini V, Marano G, Catalano L, Pupella S, Grazzini G (2018): Prevalence, incidence and residual risk of transfusion-transmitted hepatitis $\mathrm{C}$ virus and human immunodeficiency virus after the implementation of nucleic acid testing in Italy: a 7-year (2009-2015) survey. Blood Transfusion, 16(5):422.
17. Makroo RN, Chowdhry M, Bhatia A, Antony M (2015): Evaluation of the Procleix Ultrio Plus ID NAT assay for detection of HIV 1, HBV and HCV in blood donors. Asian J Transfus Sci., 9(1):29-30.

18. Yang H, Anderson S A, Forshee R, Williams A, Epstein J S, Marks P W (2016): Modeling complete removal of risk assessment questions in the USA predicts the risk of HIV exposure in blood recipients could increase despite the use of nucleic acid testing. Vox Sanguinis., 110(4): 324328.

19. Mangwana S, Bedi N (2016): Significance of nucleic acid testing in window period donations: Revisiting transfusion safety in high prevalence-low resource settings. Journal of Pathology of Nepal., 6 (11): 906-909.

20. Chigurupati P, Murthy K S (2015): Automated nucleic acid amplification testing in blood banks: An additional layer of blood safety. Asian Journal of Transfusion Science, 9(1): 9-12. 